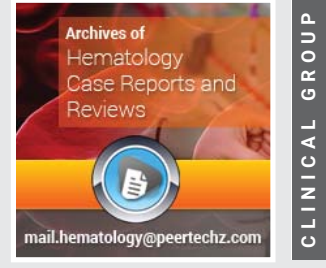

Research Article

\title{
Utility of CD38+ T-cell activation patterns determined by flow cytometry for prediction of classic Hodgkin lymphoma
}

\author{
Kelley Taylor ${ }^{1}$, Sally Ullery ${ }^{2}$, Joe Papiez ${ }^{3}$, Ron Thomason ${ }^{3}$ \\ and Ron Lee ${ }^{3 *}$
}

'East Alabama Medical Center, Opelika, AL, USA

IIntegrated Oncology, Brentwood, TN, USA

${ }^{3}$ Esoterix Pathology Practice Group, Brentwood, TN, USA

Received: 09 March, 2020

Accepted: 14 May, 2020

Published: 15 May, 2020

*Corresponding author: Ron Lee, MD, Esoterix Pathology, Practice Group, Brentwood TN, USA,

E-mail: ronlee100@outlook.com

Keywords: CD38, Hodgkin lymphoma, Flow cytometry, T-cells, Utility

https://www.peertechz.com

\section{Check for updates}

\begin{abstract}
Objectives: Classic Hodgkin lymphoma ( $\mathrm{CHL}$ ) is not typically diagnosed by routine clinical flow cytometry in most laboratories. While the neoplastic Hodgkin lymphoma/ Reed Sternberg (HRS) cells in CHL may be identified by flow cytometry using special procedures, the methodology used is not common. We observed increased CD38 expression on T-cells compared to Bcells/non-T-cells in cases of CHL compared to normal samples and confirmed our observations in the context of retrospective and prospective analyses. We identified and characterized distinctive features of background non-neoplastic $T$ cells associated with classic Hodgkin lymphoma utilizing common antibodies and analysis methods.
\end{abstract}

Methods: Cases were retrospectively identified using a search for Hodgkin lymphoma in the Interpretation or comments of reports and prospectively identified with characteristic CD38 expression patterns on non-neoplastic cells and correlated with subsequent morphologic diagnoses.

Results: Retrospective and prospective analyses were identical with respect to predictability of $\mathrm{CHL}$ using the pattern analysis described in this paper. Retrospective and prospective analyses predicted the presence of $\mathrm{CHL}$ in $82 \%$ of cases. There is a statistically significant difference between non-neoplastic T-cells and B-cells/non-Tcells in cases of $\mathrm{CHL}$ compared to normal lymph nodes.

Conclusions: There is a distinctive background pattern of non-neoplastic cells associated with most cases $\mathrm{CHL}$ ( $82 \%$ in our analyses). There is a statistically significant difference between cases of $\mathrm{CHL}$ and normal lymph nodes with respect to the expression of CD38 on non-neoplastic T-cells and B-cells.

\section{Introduction}

Classic Hodgkin lymphoma (CHL) is not typically identified by routine clinical flow cytometry in most laboratories. While CHL and Hodgkin lymphoma/ Reed Sternberg (HRS) cells may be identified by flow cytometry utilizing special techniques, the methodology used is not commonly utilized by most clinical laboratories. We identified and characterized distinctive features of background non-neoplastic cells associated with CHL using common antibodies and analysis methods.

The background milieu of CHL has been described by some as a "cytokine soup." In this context, an increase in the expression of $\mathrm{CD} 38$ on T-cells as a feature of activation appears to be predictive of Hodgkin lymphoma. Specifically, CD38 is upregulated on T-cells (predominantly CD4+ T-cells) and, when compared to background B-cells, has significantly different patterns of $\mathrm{CD} 38$ expression compared to nonneoplastic lymph nodes (Image 1). Recognizing these patterns can be useful for potentially identifying cases of CHL by flow cytometry while not specifically isolating HRS cells with special techniques. In this paper, we describe the background changes that are often seen in association with CHL utilizing commonly used antibodies and analysis methods. 
There is upregulation of CD38 on non-neoplastic T-cells in cases of CHL compared to normal lymph nodes. Observations of these general patterns prompted us to investigate quantitative analyses of these patterns (Image 2).

\section{Materials and methods sample acquisition and proces- sing}

Tissue samples were submitted by referring facilities for clinical flow cytometric evaluation for non-Hodgkin lymphoma. Tissue samples were processed according to standard accepted methods for flow cytometric evaluation per CLIA and CAP standards in our CLIA certified/ CAP accredited laboratory.

\section{Flow cytometry}

Flow cytometry was performed on processed samples using a 3 laser, 4-2-2 configuration, 8color Beckton Dickinson (BD; San Jose, CA) Canto II flow cytometer using the flowing laserfluorochrome combinations: (1) 405-nm violet laser (2 colors), BD Horizon V450 and BD Horizon V500; (2) 488$\mathrm{nm}$ blue laser (4 colors), fluorescein isothiocyanate (FITC), phycoerythrin (PE), peridinin chlorophyll protein/cyanine dye (PerCP-Cy5.5), and phycoerythrin/cyanine dye (PECy7; (3) 633-nm red laser (2 colors), allophycocyanin (APC), and allophycocyanin /cyanine dye analog (APC-H7).

The fluorescently labeled antibody cocktails used in this study were all manufactured by Beckton Dickinson.

Prior to Nov 3, 2011, relevant combinations/tubes used to compare $\mathrm{CD} 38$ expression included:

- FMC-7-FITC (FMC7), CD23-PE (EBVCS-5), CD19-
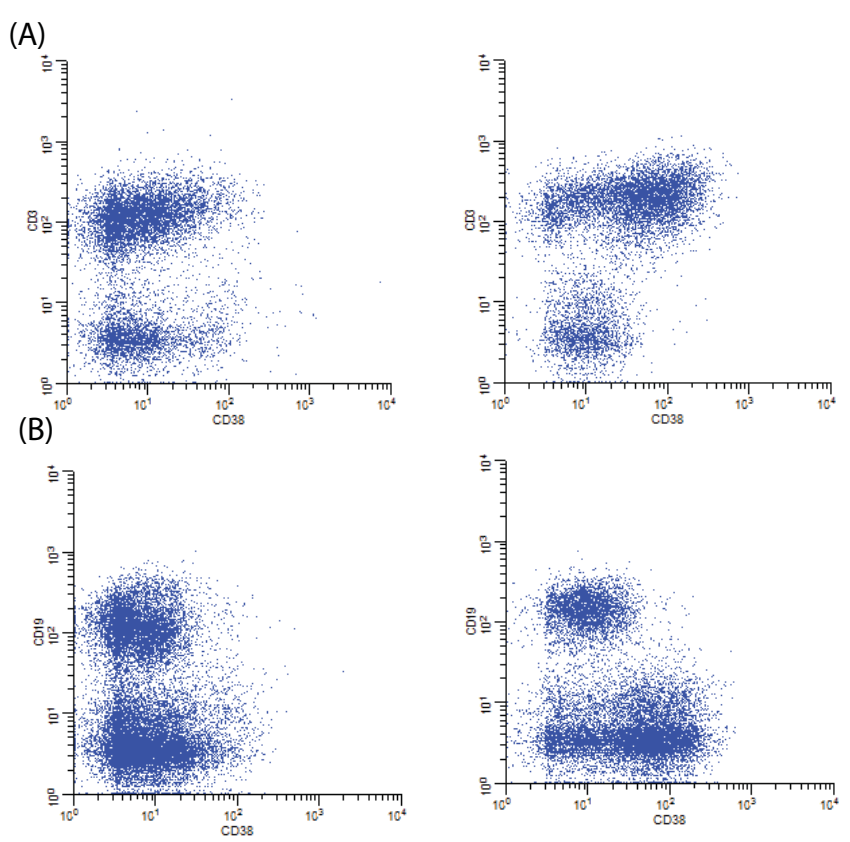

Image 1: Examples of CD38 expression patterns on T-cells compared to B-cells in normal lymph node compared to $\mathrm{CHL}$.

A. Normal lymph node (left) compared to $\mathrm{CHL}$ (right) showing general expression patterns of CD38 on T-cells (CD3+) and non T-cells (CD3-, B-cells and NK cells).

B. Case of classical Hodgkin lymphoma showing increased CD38 expression pattern on non B-cells (CD19-, T-cells and NK cells) compared to B-cells (CD19+).
(A)
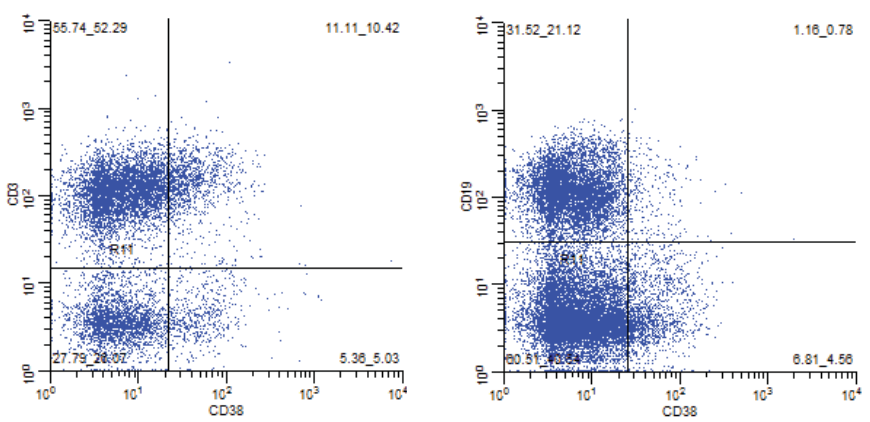

(B)
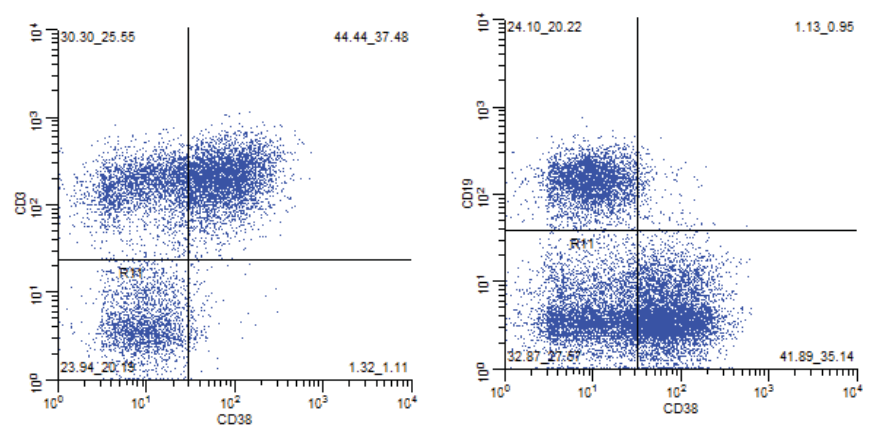

Image 2: Examples of CD38 expression on T-cells and B-cells in normal sample and $\mathrm{CHL}$ with examples of ratio calculations.

A. Normal lymph node - example of ratio calculations comparing T-cells (CD3+) to non T-cells (CD3-, B-cells and NK cells)(left) and B-cells (CD19+) to non B-cells (CD19-, T-cells and NK cells)(right)(lymphocyte gate).

On the left, T-cells are compared to non-T-cells. CD3+/CD38+ bright is compared to CD3-/CD38+ bright. The T-cell to non T-cell ratio (CD3+/CD38+:CD3-/CD38+ ratio) for the brightest CD38+ cells is $2.1(11.11 / 5.36)$.

On the right, non-B-cells (essentially T-cells) are compared to B-cells. CD19-/CD38+ bright is compared to CD19+/CD38+ bright. The non B-cell to B-cell ratio (CD19-/ CD38:CD19+/CD38+ ratio) for the brightest CD38+ cells is $5.9(6.81 / 1.16)$.

B. Case of $\mathrm{CHL}$ - example of ratio calculations comparing T-cells (CD3+) to non T-cells (CD3-, B-cells and NK cells)(left) and B-cells (CD19+) to non B-cells (CD19-, T-cells and NK cells)(right)(lymphocyte gate).

On the left, T-cells are compared to non-T-cells. CD3+/CD38+ bright compared to CD3-/CD38+ bright. The T-cell to non T-cell ratio (CD3+/CD38+:CD3-/CD38+ ratio) for the brightest CD38+ cells is 34 (44.44/1.32).

On the right, non-B-cells (essentially T-cells) are compared to B-cells. CD19-/CD38+ bright is compared to CD19+/CD38+ bright. The non B-cell ratio (essentially T-cells) to B-cell ratio (CD19-/CD38+: CD19+/CD38+ ratio) for the brightest CD38+ cells is $37(41.89 / 1.13)$.

PerCP-Cy5.5 (SJ25C1), CD5-PE-Cy7 (L17F12), CD38-APC (HB-7), CD45-APC-H7 (2D1), CD3-V450 (UCHT1)

- CD38-FITC (HB-7), CD11b-PE (D12), CD34-PerCPCy5.5 (8G12), CD117-PE-Cy7 (104D2), CD13-APC (WM15), CD45-APC-H7 (2D1), HLA-DR-V450 (L243), CD20-V500 (L27).

After Nov 3, 2011, relevant combinations used to compare CD38 expression included:

- CD57/FITC (HNK-1), CD8/PE (SK 1), 7-AAD, CD3/PECy7 (SK7), CD4/APC (SK3), CD45/APCH7 (2D1), CD38/ V450 (HB7)

- Kappa/FITC (TB 28-2), CD10/PE (HI 10A), 7-AAD, CD19/ PE-Cy7 (SJ25C1), CD43/APC (1G10), CD45/APC-H7 (2D1), CD38/V450 (HB7), CD20/V500 (L27). 
The tubes utilized were preexisting combinations typically used for screening for hematolymphoid neoplasia as part of a complete panel per established flow cytometry protocols. The tubes were chosen so T-cells (CD3+) could be compared to non-T-cells (predominantly B-cells, $\mathrm{CD} 19+$ or $\mathrm{CD} 20+$, and few NK cells), CD38 expression could be directly assessed on CD4+ and CD8+ T-cells, and/or B-cells (CD19+ or CD20+) could be compared to nonB-cells (predominantly T-cells, $\mathrm{CD}_{3}+$, and few NK cells) (Images 1-3). The different combinations utilized provided alternative ways to compare $\mathrm{CD} 38$ expression on T-cells compared to non-Tcells and assess for the patterns typically seen in association with CHL.

To determine ratios, cursors were placed to compare the subsets of cells with the brightest $\mathrm{CD} 38$ expression (Image 2). If the typical pattern seen in cases of CHL was present, cursor placement typically corresponded to a value of $1 \%$ for non-Tcells. For normal cases, which did not have the pattern present, cursor placement corresponded to a value of less than $10 \%$ for non-T-cells (typically $5 \%$ or less).

Appropriate controls were used in addition to 7-AAD (separate tube prior to Nov 2011) for exclusion of non-viable elements. Only cases with sufficient cellularity were included (typically greater than 10,000 events per tube). Data were analyzed using WinList 3D, version 7.1, Verity Software House.

\section{Retrospective analysis 1}

An initial retrospective analysis consisted of a search of all tissue cases submitted for routine clinical flow cytometric analysis for evaluation for non-Hodgkin lymphoma interpreted by Esoterix Pathology Practice Group (EPPG) in Brentwood, TN (technical component performed by Integrated Oncology, Brentwood, TN) from May 1, 2010 - Nov 10, 2010 that were reported with the term "Hodgkin lymphoma" in which the reports had "suspicious for, suggestive of, or may represent Hodgkin lymphoma" in the Interpretation or Comments (based on the observation of increased CD38 expression on T-cells in cases of Hodgkin lymphoma). 51 cases were found where there was mention of the possibility of Hodgkin lymphoma based primarily on an increased proportion of relatively bright CD38 on $\mathrm{T}$-cells compared to B-cells (typically 10:1 or greater) (Images 1 and 2) and secondarily on increased $\mathrm{CD} 4: \mathrm{CD} 8$ ratio (upper limit reference range for $\mathrm{CD} 4: \mathrm{CD} 8$ in lymph node samples is 11 in our facility with an $\mathrm{N}=40$, a mean of 5.3 , and SD of 2.7), a relative paucity of $\mathrm{B}$-cells with no overt abnormal light chain expression/clonality, no increase in $\mathrm{CD} 4+/ \mathrm{CD} 57+$ coexpression (associated with nodular lymphocyte predominant Hodgkin lymphoma), and/or no immunophenotypically abnormal Bcell or T-cell population. All corresponding morphologic diagnoses were confirmed via telephone and/or facsimile communication with the submitting pathologists.

\section{Retrospective analysis 2}

A second retrospective analysis was performed with morphologic correlation from a single institution (private pathology practice, unnamed) and consisted of identification of all tissue samples submitted to EPPG from this private
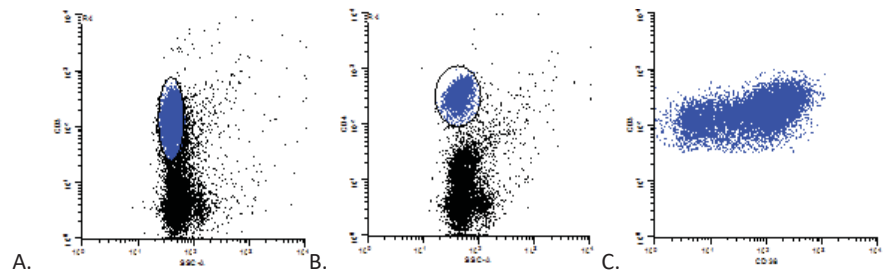

$\begin{array}{cr}\text { geoMeanX } & \text { MedianX } \\ 128.09 & 138.60\end{array}$

Image 3: T-cell mean and median values (A. CD3+ gating, B. CD4+ gating, C. Example of CD38 expression geometric mean and median for CD3+ T-cells).

A. Example of CD3+ gating (CD3 v SSC) to determine mean and median CD38 fluorescence (as shown in $\mathrm{C}$ ).

B. Example of CD4+ gating (CD4 v SSC) to determine mean and median CD38 fluorescence.

C. CD38 mean and median fluorescence as determined by gating on CD3+ cells as shown in A (mean and median fluorescence calculated by WinList software)

practice group for routine clinical flow cytometric analysis for evaluation for non-Hodgkin lymphoma from January 20, 2010 to November 28, 2011 with concurrent tissue morphologic evaluation ( $\mathrm{N}=98)$. Flow data were reviewed independent of morphologic evaluation to determine whether an increase in $\mathrm{CD} 38$ expression on T-cells was present and no immunophenotypically abnormal populations were present. Morphologic cases were also searched at the submitting institution for any cases of Hodgkin lymphoma where flow cytometry may have been signed out as negative $(\mathrm{N}=1)$ (samples from bone marrow and peripheral blood were not included) (reviewed by a single hematopathologist).

\section{Prospective analysis}

All tissue cases submitted for flow cytometry from Aug 6, 2014 - Mar 25, 2015 were screened primarily for an increased proportion (a ratio of greater than 10:1) of relatively bright CD38 seen on T-cells and secondarily for an increased CD4:CD8 ratio (typically $>5: 1$ ), no overt $\mathrm{B}$-cell light chain abnormality or abnormal T-cell population, or the presence of increased $\mathrm{CD}_{4+}+$ CD57+ coexpression (often seen in cases of nodular lymphocyte predominant Hodgkin lymphoma). 57 cases were identified based on the above and signed out as "Atypical findings" with commentary as follows (or slightly modified) (based on the findings from Retrospective Analysis 1):

"There is an increased proportion of T-cells with relatively bright CD38 (feature of activation).

There is no B-cell light chain abnormality detected Similar results are often associated with Hodgkin lymphoma. Less often, similar results may be seen in cases of large cell non-Hodgkin lymphoma where the neoplastic cells are not adequately represented by the flow data or as secondary/reactive changes in non-neoplastic lymph nodes (non-specific reactive changes, granulomatous disease/sarcoidosis, etc.). Correlation with all available clinical, laboratory, and morphologic data is necessary." When cases meeting screening criteria as suspicious for Hodgkin lymphoma were identified and signed out as "Atypical findings" with the above Comments, submitting pathologists were called and the morphologic diagnosis was obtained when available. "Normal" samples were also verified

Citation: Taylor K, Ullery S, Papiez J, Thomason R, Lee R (2020) Utility of CD38+ T-cell activation patterns determined by flow cytometry for prediction of classic 
by telephone communication with the submitting pathologists/ institutions. Statistical comparison was determined by T-test analysis (Excel 2013).

\section{CD38 Expression, mean and median values on T-cells and B-cells}

Also within this prospective analysis, 20 confirmed cases of CHL (of the 47 confirmed cases) and 20 normal cases (of the normal cases) were further analyzed evaluating the geometric mean and median levels of coexpression of CD38 on B-cells and T-cells. These values were obtained by gating on the specific cell population and plotting the respective marker vs CD38 (Image 3). Mean and median expression values were calculated by the analysis software (WinList 3D, version 7.1, Verity Software House). Statistical comparison was determined by T-test analysis (Excel 2013) between normal and confirmed Hodgkin data sets.

Case of CHL, example of mean and median CD38 fluorescence obtained by specific population gating.

Examples of $\mathrm{CD}_{3}+$ and $\mathrm{CD}_{4}+\mathrm{T}$-cell gating strategies are shown in $\mathrm{A}$ and $\mathrm{B}$ to determine the mean and median fluorescence of $\mathrm{CD} 38$ expression on all $\mathrm{T}$-cells and $\mathrm{CD} 4+$ $\mathrm{T}$-cells. The mean and median fluorescence of $\mathrm{CD} 38$ expression resulting from such specific gating is shown in $\mathrm{C}$.

\section{Results}

\section{Retrospective analysis 1}

Of the 51 cases identified (see "Materials and Methods") that were reported with the term

"Hodgkin lymphoma" in which the reports had "suspicious for, suggestive of, or may represent Hodgkin lymphoma" in the Interpretation or Comments (based on the observation of increased $\mathrm{CD} 38$ expression on T-cells in cases of classical Hodgkin lymphoma):

- 42 cases were confirmed as classic Hodgkin lymphoma $(82 \%)$,

- 3 were signed out as diffuse large B-cell lymphoma,

- 3 were reported as large B-cell lymphoma (but the description was not clear or supported very well with respect to the differential diagnosis of nodular lymphocyte predominant Hodgkin lymphoma versus $\mathrm{T}$-cell rich, histiocyte rich large B-cell lymphoma),

- 1 was inconclusive, suspect Hodgkin, sample size precluded definitive diagnosis (limited tissue core biopsy),

- 1 was inconclusive as large B-cell lymphoma versus nodular lymphocyte predominant Hodgkin lymphoma, sample size precluded definitive diagnosis (limited tissue core biopsy), and

- 1 case had no confirmation of diagnosis.
Based on this initial retrospective analysis, we confirmed presumptive observations of an association between increased CD38 coexpression on T-cells compared to B-cells/non-Tcells and classical Hodgkin lymphoma.

\section{Retrospective analysis 2}

Of the 98 cases identified (see "Materials and Methods") that had morphologic correlation for all tissue cases submitted from a single, outside institution for flow cytometry for evaluation for non-Hodgkin lymphoma:

- 4 cases exhibited the flow cytometry patterns typically associated with CHL and were consistent with $\mathrm{CHL}$ morphologically,

- 93 cases did not have the flow cytometry patterns typically associated with $\mathrm{CHL}$ and there was no morphologic evidence of CHL, and

- 1 case did not have the flow cytometry patterns typically associated with CHL but was morphologically consistent with CHL,

- no cases exhibited the flow cytometry patterns typically associated with CHL without having features of CHL morphologically.

The sensitivity and specify were calculated along with the positive predictive value (PPV), and the negative predictive value (NPV).

Based on retrospective analysis 2, the following were calculated:

Sensitivity $=80 \%$

Specificity $=100 \%$

Positive predictive value $=100 \%$

Negative predictive value $=99 \%$

Prospective Analysis

Of 57 cases that had flow cytometry patterns typically associated with CHL (Table 1), 47 were confirmed as CHL based on morphology (Table 2) (nodular sclerosis, mixed cellularity, lymphocyte rich, lymphocyte depleted, not specified). 10 were not definitively diagnosed as CHL and included:

- 1 differential diagnosis DLBCL versus CHL

- 1 PTCL versus ALCL

- 3 atypical, suspicious for HL

Table 1: Sensitivity and Specificity, Retrospective Analysis 2

\begin{tabular}{|c|c|c|c|}
\hline & \multicolumn{2}{|c|}{ HL by histology } & \multirow{2}{*}{ Totals } \\
\hline HL by pattern on flow & Positive & Negative & \\
\hline Positive & 4 & 0 & 4 \\
\hline Negative & 1 & 93 & 94 \\
\hline Totals & 93 & 5 & 98 \\
\hline
\end{tabular}

Citation: Taylor K, Ullery S, Papiez J, Thomason R, Lee R (2020) Utility of CD38+ T-cell activation patterns determined by flow cytometry for prediction of classic Hodgkin lymphoma. Arch Hematol Case Rep Rev 5(1): 011-019. DOI: https://dx.doi.org/10.17352/ahcrr.000023 
Table 2: Prospective Analysis-Comparison of Hodgkin Pattern to Normal.

\begin{tabular}{|c|c|c|c|c|}
\hline & Normal & Hodgkin Pattern & Total & P-Value \\
\hline \multicolumn{5}{|c|}{ Events } \\
\hline Mean \pm SD & $9833 \pm 763$ & $10000.0 \pm 0.0$ & $9915 \pm 550$ & 0.096 \\
\hline Median & 10000 & 10000 & 10000 & \\
\hline Min-Max & $6000-10000$ & $10000-10000$ & $6000-10000$ & \\
\hline $\mathrm{N}$ & 60 & 57 & 117 & \\
\hline \multicolumn{5}{|c|}{ Viability } \\
\hline Mean \pm SD & $91 \pm 5$ & $87 \pm 12$ & $89 \pm 9.2$ & 0.008 \\
\hline Median & 93 & 91 & 92 & \\
\hline Min-Max & $76-98$ & $30-98$ & $30-98$ & \\
\hline $\mathrm{N}$ & 60 & 57 & 117 & \\
\hline \multicolumn{5}{|c|}{$\%$ lymphs } \\
\hline Mean \pm SD & $92 \pm 11$ & $90 \pm 8.3$ & $91 \pm 10$ & 0.26 \\
\hline Median & 96 & 93 & 95 & \\
\hline Min-Max & $38-99$ & $62-99$ & $38-99$ & \\
\hline $\mathrm{N}$ & 60 & 57 & 117 & \\
\hline \multicolumn{5}{|c|}{ CD4:CD8 ratio } \\
\hline Mean \pm SD & $5.2 \pm 2.2$ & $7.7 \pm 6.8$ & $6.4 \pm 5.1$ & 0.011 \\
\hline Median & 4.9 & 6.1 & 5.4 & \\
\hline Min-Max & $2.2-11$ & $1.3-35$ & $1.3-35$ & \\
\hline $\mathrm{N}$ & 60 & 57 & 117 & \\
\hline \multicolumn{5}{|c|}{ CD4/CD57 (\% of sample) } \\
\hline Mean \pm SD & $3.0 \pm 2.4$ & $3.0 \pm 3.3$ & $3.0 \pm 2.9$ & 0.93 \\
\hline Median & $2.0 \mathrm{c}$ & 1.6 & 1.8 & \\
\hline Min-Max & $0.4-13$ & $0.3-14$ & $0.3-14$ & \\
\hline $\mathrm{N}$ & 60 & 57 & 117 & \\
\hline \multicolumn{5}{|c|}{ Polytypic B-cells (\% of sample) } \\
\hline Mean \pm SD & $30 \pm 12$ & $21 \pm 12$ & $26 \pm 13$ & $<0.0001$ \\
\hline Median & 30 & 20 & 24 & \\
\hline Min-Max & $6-57$ & $0.1-57$ & $0.1-57$ & \\
\hline $\mathrm{N}$ & 60 & 57 & 117 & \\
\hline \multicolumn{5}{|c|}{ CD3+/ CD38+ v CD3-/CD38+ } \\
\hline Mean \pm SD & $2.1 \pm 1.6$ & $22 \pm 20$ & $12 \pm 17$ & $<0.0001$ \\
\hline Median & 1.7 & 17 & 4.4 & \\
\hline Min-Max & $0.4-8.5$ & $3.3-118$ & $0.4-118$ & \\
\hline $\mathrm{N}$ & 60 & 57 & 117 & \\
\hline \multicolumn{5}{|c|}{ CD19-/CD38+ v CD19+/CD38+ } \\
\hline Mean \pm SD & $3.4 \pm 2.5$ & $41 \pm 37$ & $21 \pm 32$ & $<0.0001$ \\
\hline Median & 2.4 & 30 & 9.1 & \\
\hline Min-Max & $0.4-10$ & $5-228$ & $0.4-228$ & \\
\hline $\mathrm{N}$ & 60 & 57 & 117 & \\
\hline \multicolumn{5}{|c|}{ NK cells } \\
\hline Mean \pm SD & $1.0 \pm 0.7$ & $0.9 \pm 1.6$ & $0.9 \pm 1.2$ & 0.82 \\
\hline Median & 0.9 & 0.5 & 0.6 & \\
\hline Min-Max & $0.2-3.9$ & $0.1-11$ & $0.1-11$ & \\
\hline $\mathrm{N}$ & 60 & 57 & 117 & \\
\hline \multicolumn{5}{|c|}{ Age } \\
\hline Mean \pm SD & $49 \pm 15$ & $44 \pm 18$ & $47 \pm 17$ & 0.20 \\
\hline Median & 51 & 40 & 46 & \\
\hline
\end{tabular}

\begin{tabular}{|c|c|c|c|c|}
\hline Min-Max & $16-71$ & $21-84$ & $16-84$ & \\
\hline N & 60 & 57 & 117 & \\
\hline F & $42(70)$ & Sex & & \\
\hline M & $18(30)$ & $28(49)$ & $70(60)$ & 0.02 \\
\hline
\end{tabular}

- 1 non-specific/non-diagnostic

- 1 NLPHL

- 1 rare atypical cells

- 1 DLBCL

- 1 sarcoid

For comparison, 60 normal/non-neoplastic cases were identified and comparable analyses were performed between cases demonstrating the pattern associated with CHL and normal cases. T-test was used to compare differences between normal and patient samples (Excel 2013).

With respect to cases with the Hodgkin pattern vs normal, highly statistically significant parameters $(\mathrm{P}<0.001)$ included (Table 2): amount of polytypic $\mathrm{B}$-cells ratio of $\mathrm{CD} 3+/ \mathrm{CD} 38+$ cells to $\mathrm{CD} 3-/ \mathrm{CD} 38+$ cells (Image 2 ) ratio of $\mathrm{CD} 19-/ \mathrm{CD} 38+$ cells to $\mathrm{CD} 19+/ \mathrm{CD} 38+$ cells (Image 2 ).

Parameters not highly significantly different $(\mathrm{P}>0.001)$ included (Table 2):

number of events

viability

$\%$ lymphocytes

4:8 ratio

CD4+/CD57+ T-cells amount of NK cells age sex

Overall PPV 47/57 = 82\%

Table 2 presents descriptive prospective analysis data (cases that express Hodgkin Pattern compared to normal.

The 47 confirmed cases of CHL were then isolated and compared to normal cases.

With respect cases confirmed as CHL vs normal, highly statistically significant parameters $(\mathrm{P}<0.001)$ included (Table 3 ): amount of polytypic B-cells ratio of $\mathrm{CD}_{3}+/ \mathrm{CD} 38+$ cells to CD3-/CD38+ cells (Image 2) ratio of $\mathrm{CD} 19-/ \mathrm{CD} 38+$ cells to CD19+/CD38+ cells (Image 2)

Parameters not highly significantly different $(\mathrm{P}>0.001)$ included (Table 3):

number of events

viability

$\%$ lymphocytes

4:8 ratio 
Table 3: Prospective Analysis- Comparison of confirmed CHL to normal cases.

$$
\text { Normal }
$$

Hodgkin

\begin{tabular}{c|c} 
Mean \pm SD & $9833 \pm 763$ \\
\hline Median & 10000 \\
\hline Min-Max & $6000-10000$
\end{tabular}

N

N
Mean $\pm S D$
Median
Min-Max
N

N

Mean \pm SD

Median

Min-Max

N

Median

$\mathrm{N}$

Median

$\mathrm{N}$

Mean \pm SD
Median

Min-Max

$\mathrm{N}$

Mean \pm SD

Median

Min-Max

N

Mean \pm SD

Median

Min-Max

$\mathrm{N}$

\begin{tabular}{c|c}
\hline Mean \pm SD & $1.0 \pm 0.7$ \\
\hline Median & 0.9 \\
Min-Max & $0.2-3.9$
\end{tabular}

N

\begin{tabular}{c|c} 
Mean \pm SD & $49 \pm 15$ \\
\hline Median & 51 \\
\hline Min-Max & $16-71$
\end{tabular}

N

F
60

42 (70)

$18(30)$

\section{Events}

10000

60

$91 \pm 5$
93
$76-98$

60

$92 \pm 11$

86

60

$$
5.2 \pm 2.2
$$$$
2.2-11
$$

60

\section{CD4/CD57 (\% of sample)}

\begin{tabular}{|c|c|c|}
\hline $0 \pm 2.4$ & $2.8 \pm 2.9$ & $2.9 \pm 2.7$ \\
\hline 2.0 & 1.6 & 1.9 \\
\hline $0.4-13$ & $0.3-13$ & $0.3-13$ \\
\hline 60 & 47 & 107 \\
\multicolumn{2}{|c}{ Polytypic B-cells (\% of sample) }
\end{tabular}

(20

30

$21 \pm 13$

$26 \pm 13$

$0.1-57$

CD3+/ CD38+ v CD3-/CD38+

\begin{tabular}{c|c|c}
\hline $1 \pm 1.6$ & $24 \pm 22$ & $12 \pm 18$ \\
\hline 1.7 & 18 & 3.4 \\
\hline $.4-8.5$ & $3.3-118$ & $0.4-11$ \\
\hline 60 & 47 & 107 \\
\hline \multicolumn{2}{|c|}{ CD19-/CD38+ v CD19+/CD38+ } \\
\hline
\end{tabular}

$4+2.5 \quad 42+38$

2.4

31

$5.0-228$

$0.4-228$

47

NK cells

$0.8 \pm 1.6$
0.5
$0.1-11$

$0.9 \pm 1.2$

$0.1-11$

47

Age

\begin{tabular}{|c|c|}
\hline $43 \pm 19$ & $46 \pm 17$ \\
\hline 38 & 47 \\
\hline $21-84$ & $16-84$ \\
\hline 47 & 107 \\
\hline Sex & \\
\hline $24(51)$ & $66(62)$ \\
\hline $23(49)$ & $41(38)$ \\
\hline
\end{tabular}

0000

07
0.096
25

107

6.7

107

1.2

107

99.5

- 98

07

$1 \pm 10$

- 99

07

9

\section{CD4+/CD57+ T-cells amount of NK cells age sex}

The following mean and median CD38 coexpression values were highly statistically significant $(\mathrm{P}<0.001)($ Table 4$)$ :

$\mathrm{CD} 4+/ \mathrm{CD} 38+$ mean, $\mathrm{CD} 4+/ \mathrm{CD} 38+$ median, CD3+/CD38+ mean, $\mathrm{CD}_{3}+/ \mathrm{CD} 38+$ median

The following mean and median CD38 coexpression values were not highly statistically significant $(\mathrm{P}>0.001)$ (Table 4):

$\mathrm{CD} 8+/ \mathrm{CD} 38+$ mean, CD8+/CD38+ median, CD19+/CD38+ mean, CD19+/CD38+ median

We observed increased CD38 expression on T-cells compared to B-cells/non-T-cells in cases of CHL compared to normal samples many years ago (Images 1 and 2). We attempted to confirm our observations in the context of retrospective and prospective analyses and subsequently share our observations such that others can hopefully recognize these patterns that should be easily reproducible in most clinical flow cytometry laboratories without adding new markers or analytical methods.

Our initial retrospective analysis (Retrospective Analysis 1) indicated a predictive value of $82 \%$ for CHL when the increased expression of $\mathrm{CD} 38$ on $\mathrm{T}$-cells as we describe was present in the absence of another lymphoid neoplasm.

Our second retrospective analysis (Retrospective Analysis 2) was performed to include all tissue cases from a single institution that were submitted for flow cytometric analysis to capture possible cases where flow cytometry may be reported as negative/normal despite the presence of CHL as determined by morphologic review. Using our criteria, this retrospective analysis showed a sensitivity of $80 \%$, specificity of $100 \%$, positive predictive value of $100 \%$, and a negative predictive value of $99 \%$ for CHL. While these may appear promising, we realize higher numbers of cases might potentially reveal a lower specificity, positive predictive value, and negative predictive value.

Our prospective analysis (Prospective Analysis) had a positive predictive value of $82 \%$ when the increased expression of $\mathrm{CD} 38$ on T-cells as we described was present in the absence of another lymphoid neoplasm. Parameters such as sensitivity, specificity, and negative predictive value in this context are not calculable as not all cases which were signed out as negative were able to be correlated with morphology. We understand the limitations here, and the primary goals of our analyses were to determine if the pattern was present, how predictive was the pattern of CHL (positive predictive value) and how different were these samples compared to normal lymph node samples.

Mean and median CD38 coexpression values were compared between cases of CHL and normal/non-neoplastic cases (Table 4). Highly statistically significant differences included mean CD4+/CD38+ coexpression, median $\mathrm{CD}_{4}+/ \mathrm{CD} 38+$ coexpression, mean $\mathrm{CD} 3+/ \mathrm{CD} 38+$ coexpression, and median $\mathrm{CD} 3+/ \mathrm{CD} 38+$ coexpression. This analysis confirmed underlying assumptions regarding the patterns we describe. 
Table 4: CD38 Expression, Mean and Median Values on T-cells and B-cells.

\begin{tabular}{|c|c|c|c|c|c|c|c|c|}
\hline & $4+/ 38+$ mean & $4+/ 38+$ median & $8+/ 38+$ mean & $8+/ 38+$ median & $19+/ 38+$ mean & $19+/ 38+$ median & $3+/ 38+$ mean & $3+/ 38+$ median \\
\hline $\begin{array}{c}\text { Normal/non-neoplastic } \\
\text { cases }\end{array}$ & 17 & 11 & 16 & 9 & 26 & 13 & 16 & 10 \\
\hline Hodgkin lymphoma & 80 & 47 & 51 & 19 & 21 & 12 & 73 & 37 \\
\hline P-value & $<0.0001$ & 0.0002 & 0.002 & 0.19 & 0.06 & 0.29 & $<0.0001$ & 0.0006 \\
\hline
\end{tabular}

Using a pattern based approach, we found the ability to predict the presence of CHL was at least $82 \%$. Our approach employs antibodies and analysis methods commonly used in most clinical flow cytometry laboratories (specifically, CD38 and common B-cell and T-cell markers), and the patterns we describe can be used to alert those interpreting flow cytometry data to a likely association with CHL.

Our findings demonstrate how antibodies commonly used by most clinical flow cytometry laboratories can be used to predict the presence of CHL. There are, however, some considerations when evaluating $\mathrm{CD} 38$ expression on T-cells. As a general marker of activation, $\mathrm{CD} 38$ can be upregulated in a variety of conditions. In particular, viral infections (EBV/ infectious mononucleosis, $\mathrm{CMV}$, etc.) can have increased $\mathrm{CD} 38$ on T-cells. But the brightest $\mathrm{CD} 38 \mathrm{~T}$-cells in these cases are typically $\mathrm{CD} 8+$, in contrast to what we typically see in cases of CHL where $\mathrm{CD} 4+\mathrm{T}$-cells typically predominate. For this reason, we routinely run $\mathrm{CD} 38$ in the same tube with $\mathrm{CD} 4$ and $\mathrm{CD} 8$. Also, in our experience, metastatic disease may have increased CD38 on T-cells, often predominated by CD8+ T-cells. Conditions in which normal $\mathrm{CD}_{4}+\mathrm{T}$-cell subpopulations are depleted or the immune response is suppressed (HIV or other causes of immunosuppression) may not show the typical $\mathrm{T}$-cells patterns we describe, even in the presence of CHL. The patterns we describe may also be seen in association with non-Hodgkin lymphoma, but if there is no definitive evidence of non-Hodgkin lymphoma, the patterns we describe are typically associated with CHL. As our data show, the patterns we describe, even when there is no definitive evidence of non-Hodgkin lymphoma, may be seen in cases of large B-cell lymphoma, T-cell lymphoma, or sarcoidosis.

\section{CD38 and other markers in cases of CHL}

The immunological role of $\mathrm{CD} 38$ has been explored widely in murine models and a whole society is devoted to elucidating its role. It can be found in multiple tissues in the body but in Tcells it "may indirectly regulate signaling by catabolizing NAD+ and altering or preventing the activity of NAD+-metabolizing enzymes such as ART2, SIRT1 and PARP" and knockout mice of $\mathrm{CD} 38$ have shown increased autoimmune functions (enhancement of antibody mediated tissue damage); however there are multiple cell types that express CD38 and different calcium dependent and independent pathways that have yet to be studied $[1,2]$. Because of the numerous cell types that express CD38 in the body, this does not appear to be a candidate for future drug therapy [2]. CD38 on T-cells is expressed preferentially at early and late stages but not in the middle/resting stage [3]. It is tightly regulated and $\mathrm{CD} 38+$ cells (in murine models) were also positive for $\mathrm{CD} 25$ and CD69, "confirming their activated status, although these markers were also seen on CD38- cells, inexplicably" [4]. Its true function is poorly understood and its murine analog, $\mathrm{CD} 39$, is "one of the first characterized but perhaps the least understood lymphocyte differentiation antigens" [3]. No CD38-negative human has been identified, implying its absence is incompatible with life. $\mathrm{CD} 38 \mathrm{KO}$ mice can live and reproduce but show "selective deficiencies of the innate and adaptive immune system" [2].

Several groups have looked at the non-neoplastic cells in CHL. Di Gaetano et al. reported anergic CD4+CD26- T lymphocytes frequently express high levels of $\mathrm{CD} 38$ in cases of CHL and that CHL cases compared to benign lymph nodes expressed significantly higher $\mathrm{CD} 38$ and showed decreased expression of CD26 with statistical significance; however, this was based on median and intraquartile ranges with no further commentary as to how to use this in practice [5]. We showed an even stronger significance when isolating $\mathrm{CD}_{3}+1$ CD38 and CD19-/CD38+ cells and analyzing the ratios of the brightest $\mathrm{CD} 38$ expressing $\mathrm{T}$-cells compared to $\mathrm{CD} 3+/ \mathrm{CD} 38-$ cells and CD19-/CD38- cells, respectively. They combined this information to demonstrate higher $\mathrm{CD}_{4}+/ \mathrm{CD} 26-/ \mathrm{CD} 38+$ cells in CHL compared to normal patients and suggested that this particular subset of T-cells could be linked to Treg cells and an inverse relationship of $\mathrm{CD} 38$ and $\mathrm{CD} 26$ in its contribution to tumor escape by HRS cells from the immune system by increasing levels of immunosuppressive adenosine [5]. We agree with this group's advocacy for an evaluation of Hodgkin microenvironment lymphocytes via flow cytometry as viable alternative for evaluation for Hodgkin lymphoma via its unique interplay with the surrounding immune system; however, CD26 is not as commonly used as CD38 in most screening clinical flow cytometry testing.

Some studies have focused on increased numbers of Treg CD4+/CD25+ cells in Hodgkin lymphoma as well as groups studying $\mathrm{T}$ regulatory 1 ( $\mathrm{T}-\mathrm{reg}, \mathrm{IL}-10$ secreting) cells working in conjunction with $\mathrm{CD} 4+\mathrm{CD} 25+$ Treg cells, both of which together inhibit an anti-tumor response [5-8]. Although regulatory $\mathrm{T}$-cells are documented in other human neoplasms, the quantitative and qualitative activity of these regulatory T-cells in CHL in particular is unique [7]. Another group looked at the increased percentage of $\mathrm{CD} 4$ bright $\mathrm{CD} 25+$ regulatory $\mathrm{T}$-cells in CHL when compared to reactive lymphoid hyperplasia. It showed that when evaluating for CD4+/CD25+ coexpression, the median percentage of $9 \%$ (percentage of total gated nongranular cells or medial normalized ratio of two cell subsets) varied significantly from reactive lymph nodes (2\%) [9].

CD152 and CD25 have also been studied in cases of CHL 
by comparing CD152 expression on $\mathrm{CD} 4+/ \mathrm{CD} 25+$ cells. Using these combinations of markers, CHL was distinguished from benign lymph nodes with $79 \%$ sensitivity and $100 \%$ specificity and again postulating that the detection of Treg cells "may be a useful tool in distinguishing CHL from other entities" [8]. They also noted that the CD4:CD8 ratio was of limited utility to distinguish between benign and malignant cases. Again, CD152 is not widely used in most clinical flow cytometry laboratories.

Other groups have looked at patterns of T-cell markers in CHL, including an increased CD4:CD8 ratio and increased CD7 on both $\mathrm{CD} 4$ and $\mathrm{CD} 8 \mathrm{~T}$-cells compared with reactive lymph nodes [10]. However, using the expression of a single T-cell marker has shown a diagnostic ability of being able to correctly diagnose HL in 37 of 47 FNA cases (78\%) of known HL and uses median values that would require further analysis and validation rather than using pattern recognition and simple ratios that we describe. We did find slightly higher CD4:CD8 ratios in cases of Hodgkin lymphoma compared to normal. Our study did not directly identify HRS cells and we did not specifically assess $\mathrm{CD} 7$ or $\mathrm{CD} 3$ expression in cases of $\mathrm{CHL}$, but we did assess $\mathrm{CD} 38$ coexpression on T-cells and showed the expression of CD38 on T-cells was highly significantly different in cases of CHL compared to normal lymph nodes.

The non-neoplastic immune cells in CHL are attracted to the cytokines released by the HRS cells and, in turn, secrete cytokines that contribute to an immune protective function to the HRS cells themselves through a complicated myriad of cytokine interactions [6]. $\mathrm{CD}_{4}+$ helper T-cells have been reported to be the majority of the cells in the CHL microenvironment (the mean CD4:CD8 ratio in our study was 5.2 in normal cases vs. 7.7 in CHL) $[6,7,9]$. These T-cells have been shown to be the TH1 (activation marker rich) variety rather than senescent $\mathrm{TH} 2$ hypofunctional T-cells [6]. A predilection for $\mathrm{CD}_{4}+$ cells in the Hodgkin microenvironment as well as Th1 cells preferentially located near RS cells has also been reported [9-16]. But HRS cells avoid the immune system by escaping apoptosis (via latent EBV infection, resulting in polymorphisms of HLA Class I to allow for escape from CD8 cells), down regulation of HLA Class I in EBV-negative cases, upgrading signaling to promote survival, altering the CD4 cells to select for favorable allies not to induce antigen presenting cell signaling, and producing soluble HLA-G to allow from escape from NK cells that otherwise would have responded to the loss of HLA Class I receptors on the surface of the HRS cell [17]. These T-cell changes in CHL are manifested in the activation of $\mathrm{T}$-cells and in the $\mathrm{T}$-cell patterns we describe.

\section{Conclusions}

T-cells in cases of classic Hodgkin lymphoma show upregulation of CD38 that is significantly different than in cases of normal lymph nodes based on pattern recognition as well the quantification of $\mathrm{CD} 38$ expression. Using our pattern recognition and analysis, we found the positive predictive value of the presence of classic Hodgkin lymphoma to be at least $82 \%$. In the absence of definitively abnormal/ neoplastic populations, such patterns should be recognized by those interpreting flow data as being frequently associated with classic Hodgkin lym- phoma and less frequently associated with other lymphomas and non-neoplastic conditions.

\section{References}

1. Lund FE (2006) Signaling properties of CD38 in the mouse immune system: enzyme-dependent and -independent roles in immunity. Molecular medicine 12: 328-333. Link: https://bit.ly/3dKMn1N

2. Malavasi $F$, Deaglio $S$, Funaro $A$, Ferrero $E$, Horenstein $A L$, et al. (2008) Evolution and function of the ADP ribosyl cyclase/CD38 gene family in physiology and pathology. Physiol Rev 88: 841-886. Link: https://bit.ly/2WqFwF2

3. Jackson DG, Bell JI (1990) Isolation of a cDNA encoding the human CD38 (T10) molecule, a cell surface glycoprotein with an unusual discontinuous pattern of expression during lymphocyte differentiation. J Immunol 144: 2811 2815. Link: https://bit.ly/3dL3GA5

4. Sandoval-Montes C, Santos-Argumedo L (2005) CD38 is expressed selectively during the activation of a subset of mature $T$ cells with reduced proliferation but improved potential to produce cytokines. J Leukoc Biol 77: 513-521. Link: https://bit.ly/2ApadC4

5. Di Gaetano R, Gasparetto V, Padoan A, Callegari B, Candiotto L, et al. (2014) Flow cytometry CD4(+)CD26(-)CD38(+) lymphocyte subset in the microenvironment of Hodgkin lymphoma-affected lymph nodes. Ann Hematol 93: 1319-1326. Link: https://bit.ly/2TOynt3

6. Greaves P, Clear A, Owen A, Iqbal S, Lee A, et al. (2013) Defining characteristics of classical Hodgkin lymphoma microenvironment T-helper cells. Blood 122: 2856-2863. Link: https://bit.ly/2ThdIBh

7. Marshall NA, Christie LE, Munro LR, Culligan DJ, Johnston PW, et al. (2004) Immunosuppressive regulatory $T$ cells are abundant in the reactive lymphocytes of Hodgkin lymphoma. Blood 103: 1755-1762. Link: https://bit.ly/2LBEb8p

8. Bosler DS, Douglas-Nikitin VK, Harris VN, Smith MD (2008) Detection of T-regulatory cells has a potential role in the diagnosis of classical Hodgkin lymphoma. Cytometry B Clin Cytom 74: 227-235. Link: https://bit.ly/2WOWf44

9. Hudnall SD, Betancourt E, Barnhart E, Patel J (2008) Comparative flow immunophenotypic features of the inflammatory infiltrates of Hodgkin lymphoma and lymphoid hyperplasia. Cytometry B Clin Cytom 74: 1-8. Link: https://bit.ly/2yVAyai

10. Seegmiller AC, Karandikar NJ, Kroft SH, McKenna RW, Xu Y (2009) Overexpression of CD7 in Classical Hodgkin LymphomaInfiltrating T Lymphocytes. Cytometry B Clin Cytom 76: 169-174. Link: https://bit.ly/2YYsHn9

11. Fromm JR, Kussick SJ, Wood BL (2006) Identification and purification of classical Hodgkin cells from lymph nodes by flow cytometry and flow cytometric cell sorting. Am J Clin Pathol 126: 764-780. Link: https://bit.ly/35VGf49

12. Fromm JR, Wood BL (2014) A six-color flow cytometry assay for immunophenotyping classical Hodgkin lymphoma in lymph nodes. Am J Clin Pathol 141: 388-396. Link: https://bit.ly/2T11nAU

13. Grewal RK, Chetty M, Abayomi EA, Tomuleasa C, Fromm JR (2019) Use of flow cytometry in the phenotypic diagnosis of hodgkin's lymphoma. Cytometry B Clin Cytom 96: 116-127. Link: https://bit.ly/2T0z05T

14. Fromm JR, Thomas A, Wood BL (2010) Increased expression of T cell antigens on T cells in classical Hodgkin lymphoma. Cytometry B Clin Cytom 78: 387388. Link: https://bit.ly/3cuaWQC

15. Roshal M, Wood BL, Fromm JR (2011) Flow cytometric detection of the classical hodgkin lymphoma: clinical and research applications. Adva Hematol 2011: 387034. Link: https://bit.ly/2yRxzjj 
16. Borowitz MJ, Croker BP, Metzgar RS (1982) Immunohistochemical analysis of the distribution of lymphocyte subpopulations in Hodgkin's disease. Cancer Treat Rep 66: 667-674. Link: https://bit.ly/3btwSKr
17. Poppema S (2005) Immunobiology and pathophysiology of Hodgkin lymphomas. Hematology Am Soc Hematol Educ Program 231-238. Link: https://bit.ly/3fLYTjG
Discover a bigger Impact and Visibility of your article publication with

\section{Peertechz Publications}

\section{Highlights}

* Signatory publisher of ORCID

* Signatory Publisher of DORA (San Francisco Declaration on Research Assessment)

- Articles archived in worlds' renowned service providers such as Portico, CNKI, AGRIS, TDNet, Base (Bielefeld University Library), CrossRef, Scilit, J-Gate etc.

* Journals indexed in ICMJE, SHERPA/ROMEO, Google Scholar etc.

- OAI-PMH (Open Archives Initiative Protocol for Metadata Harvesting)

* Dedicated Editorial Board for every journal

* Accurate and rapid peer-review process

* Increased citations of published articles through promotions

* Reduced timeline for article publication

Submit your articles and experience a new surge in publication services

(https://www.peertechz.com/submission).

Peertechz journals wishes everlasting success in your every endeavours.

Copyright: @ 2020 Taylor K, et al. This is an open-access article distributed under the terms of the Creative Commons Attribution License, which permits unrestricted use, distribution, and reproduction in any medium, provided the original author and source are credited.

Citation: Taylor K, Ullery S, Papiez J, Thomason R, Lee R (2020) Utility of CD38+ T-cell activation patterns determined by flow cytometry for prediction of classic Hodgkin lymphoma. Arch Hematol Case Rep Rev 5(1): 011-019. DOI: https://dx.doi.org/10.17352/ahcrr.000023 